\title{
Human Intestinal Microbiome and the Immune System: The Role of Probiotics in Shaping an Immune System Unsusceptible to COVID-19 Infection
}

\author{
T. V. Belkina ${ }^{a, *}$, O. V. Averina ${ }^{a}$, E. V. Savenkova ${ }^{b}$, and V. N. Danilenko ${ }^{a, b}, * *$ \\ ${ }^{a}$ Vavilov Institute of General Genetics, Russian Academy of Sciences, Moscow, Russia \\ ${ }^{b}$ International Institute for Strategic Development of Sectoral Economics, Peoples' Friendship University of Russia (RUDN), \\ Moscow, Russia \\ *e-mail: belkA25t@gmail.com \\ **e-mail: valerid@vigg.ru
}

Received September 2, 2020; revised September 2, 2020; accepted September 2, 2020

\begin{abstract}
Today, the human gastrointestinal microbiota (HGM) is seen as an organ that orchestrates the activity of all other organs and systems (namely the brain) and one that plays a major role in maintaining homeostasis of the host organism. A remarkable ability of the HGM as a key player in the development of a normal immune system is its ability to recognize stress signals in its environment, e.g., triggers by viruses and other pathogenic microorganisms, and to react accordingly. SARS-CoV-2, the causative agent of COVID-19 disease, represents an unfamiliar type of virus to the human organism due to a lack of regular encounters between them over the course of evolution. This is one possible explanation of the disproportionate response of both innate and acquired immune systems seen in many people. In this review, we analyze certain immunomodulatory aspects of the HGM. We also assess the state of research in the field of next-generation probiotics, such as pharmacbiotics and postbiotics, and their potential use for the prevention and treatment of COVID-19. The range of symptoms typical of COVID-19 infection is presented in a concise form. The impact of COVID-19 infection on various organs and systems will be examined in future studies. Nevertheless, although we are in the early stages of the pandemic, we can still predict that COVID-19 will have a large impact of on the incidence of tuberculosis and depression in various populations around the world. The HGM, depending on whether it is normal or dysfunctional (dysbiosis), can be an important predictor of the efficacy of COVID-19 vaccines. These factors need to be taken into account, and, perhaps, a set of measures for the rehabilitation of certain groups of the population should be adopted. These measures should include the development of next-generation pharmacbiotics (psychobiotics, probiotics exhibiting antioxidant properties, immunobiotics), as well as specialized functional foods.
\end{abstract}

Keywords: COVID-19, immunomodulatory potential, probiotics, lactobacilli, gastrointestinal microbiome DOI: $10.1134 / \mathrm{S} 2079086421040034$

\section{INTRODUCTION}

The renaissance of interest in the bacteria inhabiting the human gastrointestinal tract (microbiota) manifested itself $10-15$ years ago, after the fact of bidirectional gut-brain communication had been established (Rhee et al., 2009; Foster and Neufeld, 2013; Averina and Danilenko, 2017; Cryan et al., 2019).

Along with the successful metagenomic sequencing of intestinal (fecal) samples, the obtainment of experimental data, and the simultaneous development of the techniques of bioinformatic data analysis, this interdisciplinary trend has become one of leading trends in the science of life (Klimina et al., 2020; Averina et al., 2020). Today, it is obvious that the gastrointestinal microbiota (the microbiome) communicates directly and indirectly with all human organs and sys- tems, being one of the key integrating mechanisms for the maintenance of homeostasis (Belkaid and Harrison, 2017; Wang et al., 2017; Grosicki et al., 2018; Kastl et al., 2020). The effects of HGM bacteria, in particular, lactobacilli, on the functions of the immune system have been known since the time of discovery of this phenomenon by the academician I.I. Mechnikov (Marco et al., 2006), and they have been studied over the past 100 years. The genus Lactobacillus is an important HGM inhabitant that exerts a substantial effect on the function of the immune system (Galdeano and Perdigón, 2006; Abdo et al., 2019).

Many lactobacillus strains belonging to more than 120 species have been used in probiotics and postbiotics (Shenderov, 2013; Marsova et al., 2020a, 2020b; Novik and Savich, 2020). The genomes of many thou- 
sands of Lactobacillus strains were sequenced, and the methods of transcriptomic, proteomic, and metabolomic analysis were used to detect the genes and their products responsible for interactions with the host organism, including the immune system (Zhang et al., 2018). Hence, it was possible to proceed from the era of probiotics to the development of pharmbiotics, drugs based on bacteria with the classical probiotic properties but with the identified active component(s), mechanisms of action, and an experimentally confirmed efficiency against particular nosological forms (Oleskin and Shenderov, 2019). There is an abundance of data indicating the role of microbiota in the development of various diseases (psychiatric, oncologic, autoimmune and infectious) (Blumberg and Powrie, 2012; Gilbert et al., 2016; Levy et al., 2017). Lactobacilli-based drugs are considered psychobiotics (Yunes et al., 2016a, 2016b, 2019; Cheng et al., 2019), probiotics exhibiting antioxidant potential (Marsova et al., 2018, 2020a, 2020b; Talib et al., 2019), and immunobiotics (Averina et al., 2015; Tada et al., 2016).

The year of 2020 saw the COVID-19 pandemic caused by the SARS-CoV-2 coronavirus. The apparent role of the HGM in the maintenance of the immune system and the significant effect of the immune system of a particular person on the course of disease compel us to take a closer look at the neuromodulating, antioxidant, and immunomodulating potentials of the HGM. The specific properties of lactobacilli as potential immunomodulating agents for the prevention and treatment of COVID-19 require further analysis of this aspect. In the present review, we attempted to bring the HGM microbiome, the immunomodulatory potential of lactobacilli, as well as other probiotic bacteria, and COVID-19 infection together into a single systemic problem.

\section{HUMAN GASTROINTESTINAL MICROBIOTA: FORMATION, DEVELOPMENT, COMPOSITION, AND MAIN FUNCTIONS}

The human microbiota is an assembly of various microorganisms inhabiting the human body (Yan and Charles, 2018). The microbiome is an assembly of the genes of all microorganisms comprising the microbiota (Turnbaugh et al., 2013; Shreiner et al., 2015).

These terms are currently considered synonyms, and the original term is microbiome.

Microorganisms begin to colonize human body at the moment of birth, when the fetus passes through the birth canal; by the third-fourth year of a child's life, its microbiota becomes similar in composition to the microbiota of adults (Lozupone et al., 2012). The replenishment and development of microflora from year to year continues until adulthood. In the case of caesarian section, the newborn's microbiota is based on bacteria from the environment but not on the vagi- nal and fecal bacteria of its mother. The microbiotas of babies born vaginally and via $\mathrm{C}$-section show the presence of undifferentiated bacterial communities of the skin, mouth cavity, nasopharynx, and gut of newborns irrespective of the means of delivery. The microbiota of unnatural born babies is similar to the mothers' skin community; natural born babies acquire bacterial communities similar to the vaginal microbiota. Other factors influencing the microbiota are the type of infant feeding, gestational age, and administration of antibiotics. Bifidobacteria are predominant in the microbiota of breastfed babies, while the amounts of Escherichia coli, Clostridium difficile, Bacteroides fragilis, and Lactobacillus are higher in formula-fed babies (Ottman et al., 2012)

The microbiota of adults is rather stable if the environment remains constant, but it changes in their old age with a decrease in compositional diversity (Lozupone et al., 2012). The human microbiota undergoes changes in response to various factors, including diet, environment, stress, medical interventions and diseases (Barko et al., 2018; Gilbert et al., 2018).

The microbiota consists of a consortium of bacteria, archaea, fungi, protozoa, and viruses, which are also present in and on human body and amount to $10^{13}-10^{14}$ microorganisms. In view of the COVID-19 pandemic, the viral component of the microbiome (virome) has begun to attract great attention (Mukhopadhya and Segal, 2019). The HGM is extremely numerous and diverse in composition. The amount of bacteria in the intestines is equal to the number of somatic cells in the body. The biomass of gut microbiota may be up to $1-2 \mathrm{~kg}$. The number of microorganisms varies between different parts of GIT: $10^{2}-10^{4}$ cells $/ \mathrm{mL}$ in the stomach, $10^{6}-10^{8}$ in the small intestine, and up to $10^{12}$ cells $/ \mathrm{mL}$ in the large intestine (Derrien and van Hylckama Vlieg, 2015). The overwhelming majority of bacteria in the human gastrointestinal tract (GIT) belong to the following three phyla: Bacteroidetes, Firmicutes, and Proteobacteria (Spor et al., 2011; Moal, 2014; Montalban-Arques et al., 2015).

Microbiomics is the developing field of research on the detection of microbiota components, analysis of the microbiome, characterization of the interactions between the microbiota and the host, and assessment of its effect on the state of human health (Fata et al., 2018). The microbiota makes a vital contribution to energy homeostasis, metabolism, the state of the intestinal epithelium, and the immunological activity of the organism, including its responses to infectious diseases.

Studies have proven the important role of the HGM in the control of brain development and function, while the immune system becomes an important regulator of these interactions. Intestinal microbes regulate the maturation and function of resident immune cells of the central nervous system (CNS), 
which protect against infections and injuries, and they maintain neurons with remodeling of chain bonding and plasticity. Microbes also influence the activation of peripheral immune cells, which regulate the responses to neuroinflammation, brain injuries, autoimmunity, and neurogenesis. Accordingly, both the microbiota and the immune system are involved in etiopathogenesis or the manifestation of neuropsychiatric and neurodegenerative diseases, such as autism spectrum disorder, depression, and Alzheimer's disease (Fung et al., 2017).

Carbohydrate fermentation is the main function of the HGM. It was shown that the metagenome of the small intestine is much more enriched in genes associated with carbohydrate metabolism as compared to the metagenome of feces. Sugar phosphotransferases, enzymes of the pentose phosphate pathway, proteins for lactate and propionate fermentation, and cofactors such as cobalamin and biotin are encoded in many taxa from iliac drains, in particular, Streptococcus. This confirms that carbohydrate balance is the central function of the collective small intestinal microbiota (Zoetendal et al., 2012). Metatranscriptomic analysis showed that metabolic processes are very active and that the microbiota of the small intestine quickly adapts to fluctuations in nutrient availability in the lumen via the fast metabolism of simple carbohydrates to maintain the life of the community. This fact contrasts with the communities of the large intestine, which are better adapted to the cleavage of complex carbohydrates (Turnbaugh et al., 2010). Streptococci are enriched with energy-generating genes and are believed to make a considerable contribution to the primary digestion of food components in the small intestine; fermentation products support the growth of other fermenters, e.g., Veillonella, Clostridium. Indeed, the coexistence of Streptococcus and Veillonella takes place not only in the intestines but also in the stomach, esophagus, throat, and mouth cavity and is probably related to their metabolic interaction and lactic-acid production and utilization (Kastl et al., 2020). Components of the microbiota are also involved in protein and lipid catabolism and the synthesis of vitamins, bacteriocins, amino acids, neurotransmitters, peptides, and regulatory RNA. The results of this activity are as follows: the supply of energy to the human body, "building blocks," and a change in the gene-transcription activity of a macroorganism. In the meantime, the excessive intake and storage of nutrients (e.g., fats) is due to low microbial diversity and changes in the relative abundance of the major bacterial phyla Bacteroidetes and Firmicutes. Though these data confirm the microbial regulation of local metabolic function, they also demonstrate that the gut microbiota can affect distal metabolic activity in skeletal muscle tissues.

The study was performed with mice born and grown under sterile conditions without the microbiome and with conventionally raised animals. As a result of the introduction of a microbiota into amicrobic mice, there was a $60 \%$ increase in body fat with a reciprocal decrease in insulin sensitivity and glucose tolerance. Since skeletal muscles are an integral component of glucose utilization, these data show that the metabolic function of muscles is regulated by microbes. In support of this view, bacterial colonization of mice reduces the metabolic efficiency of skeletal muscles, as is demonstrated by the increase in the amounts of intermediates of the tricarboxylic-acid cycle without a noticeable increase in the reserves of high-energy phosphate. The activity of skeletal muscle proteins and gene expression were also compared. As compared to conventionally raised mice, the skeletal muscles of mice lacking a microbiome were characterized by a noticeably higher activity of AMP-activated protein kinase (AMPK) and carnitine palmitoyltranferase-1 (CPT-1), demonstrating an enhanced oxidative capacity. Taken together, these early studies show that the gut microbiota can influence body composition via the regulation of the bioenergetic pathways of skeletal muscles (Grosicki et al., 2018).

The metabolites produced by GIT microorganisms also exert an effect on distal organs, such as the lungs (Wang et al., 2017). The microaspiration of intestinal bacteria or the transfer of sensitized immune cells by lymph or blood flow influences the immunoresponse of other organs. Dysbiosis of the gut microbiota is associated with several lung diseases, including allergy, asthma, and cystic fibrosis. The bidirectional interaction between the gut and the lungs is best illustrated by the intestinal disorders observed with lung disease. For example, the decreased number of Bifidobacteria and the increased number of Clostridia in the intestines are associated with early-age asthma. In addition, mouse studies showed that the depletion of certain species in the gut microbiota as a result of antibiotic administration influences lung diseases and allergic inflammation (Dharmage et al., 2015). Changes in the pulmonary microbial community also affect the composition of the gut microbiota. For example, the viral dynamics of influenza in respiratory tracts (as shown in mouse models) increases the amount of Enterobacteriaceae and decreases the amount of lactobacilli and lactococci in the gut microbiota. Dysbiosis of the lung microbiota upon the introduction of lipopolysaccharide (LPS) in mice is accompanied by gut-microbiota disorders due to the transfer of bacteria from lungs with the blood flow (Sze et al., 2014).

All of the mentioned results confirm that the gut and lungs are complexly related organs that influence the homeostasis of each other. The human body seems to have not a single organ or system that would not be directly or indirectly associated with the function of the gut microbiota. 


\section{MICROBIOTA AND IMMUNE SYSTEM}

The interactions between the microbiota and the host immune system are polymodal, complex, and bidirectional. From the moment of birth, the human microbiota, primarily, the gut microbiota, plays the decisive role in the induction, training, and function of the immune system (Belkaid and Harrison, 2017). In turn, the immune system develops as a tool that supports partnerships with commensal and symbiotic microorganisms and induces protective inflammatory responses to pathogens, i.e., the immune system learns to coexist with commensal microbiota and to respond adequately to pathogenic microorganisms (Hooper et al., 2012). The disturbance of intestinal homeostasis can lead to diseases such as cancer, Crohn's disease (regional enteritis), nonspecific ulcerative colitis, diabetes, obesity, allergy, asthma, etc. (Cianci et al., 2018). The development of these diseases also correlates with impaired functions of the immune system (Fedorova and Danilenko, 2014).

The intestines are an important immunological organ. About $80 \%$ of all immunocompetent cells are localized in the intestinal mucus; about $25 \%$ of the mucous membrane consists of immunologically active tissue and cells. Morphologically, the gut-associated lymphoid tissue (GALT) includes cellular (macrophages, plasma and mast cells, lymphocytes, etc.) and structural elements (lymphoid follicles, lymph nodes, Peyer's patches, etc.). The latter, which are controlled by cells of immunological memory, are involved in the interaction between antigen-presenting cells (APCs), which are capable of antigen absorption or processing, and $\mathrm{T}$ cells, thereby carrying out the immunoresponse. An important GALT function is antigen identification and the removal or development of immunological tolerance to antigens (Yarilin, 2010).

Toll-like receptors (TLRs) are the transmembrane molecules binding extra- and intracellular structures and are elements of the immune protection of the intestinal epithelium. They perform an important function in the immune response: they detect particular structures of the antigens of intestinal bacteria and bind them. TLR receptors provide tolerance to constant microflora, APC-antigen delivery, an increased gap-junction density, and the induction of antimicrobial peptides (Lu et al., 2018). In addition, TLRs can be receptors for cytokines such as interleukin-1 (IL-1), IL-13. At present, there are 13 known TLRs. In mammals, the most important is TLR4. This receptor of bacterial endotoxins plays the key role in the induction of innate immunity and inflammation. TLR4 is activated by bacterial LPS due to the coordinated and successive effects of three other proteins: lipopolysaccharide-binding protein (LPP), cluster of differentiation antigen CD14, and myeloid differentiation protein MD-2 receptors. The latter bind LPS and present it to TLR4 in monomeric form by forming an active complex [TLR4·MD-2·LPS] (Gómez-Llorente et al.,
2010). Moreover, immunoglobulins of all classes are found in the gut of adults (secretory immunoglobulins A (IgA) being predominant). The proven effect of gut microbiota on immune adaptation and the development of human tolerance to external factors allowed the use of microorganism-human symbionts for the prevention and treatment of quite a number of diseases (Peri et al., 2012). In 2020, COVID-19 became a threat to the world population, and its study has given high relevance to the role of the gut microbiota in the course and treatment of this disease.

\section{COVID-19: A TOTAL THREAT \\ TO THE IMMUNE SYSTEM THAT LEADS TO THE DESTRUCTION OF MANY ORGANS}

Today, the world is gripped by the pandemic of the new coronaviral infection, COVID-19, caused by the SARS-CoV-2 virus. Thus pathogen has rapidly spread all over the world since the first outbreak in Wuhan (China) in December 2019.

SARS-CoV-2 is a new type of coronavirus of the family Coronaviridae, an enveloped RNA virus. The average incubation period is 5-14 days; the basic reproduction number is estimated to be $2.1-3.4$ (Weiss et al., 2005; Li et al., 2019; Gralinski and Menachery, 2020; Wang et al., 2020).

It is known that COVID-19 binds to the angiotensin-converting enzyme 2 (ACE2) and its receptor (Yan et al., 2020). ACE2 is one of the regulators of inflammatory processes, including those in the gut (Zhang et al., 2020).

An important factor in the development of coronaviruses and SARS-CoV-2 is, in particular, their active replication in epithelial cells and the enhanced expression of proinflammatory cytokines and chemokines, which leads to pathogenetic effects. The possible scenario for the development of clinical manifestations in $15 \%$ of cases is acute respiratory distress syndrome, a life-threatening pulmonary inflammatory lesion and fibrosis of the alveolar tissue. The second important aspect is the predominant viral infection of respiratory epithelium and alveolar epithelium. Due to activation of the NSP genes, the virus actively escapes the innate immunoresponse and delayed interferon response, which indicates the formation of inflammatory response (Zumla et al., 2015; Walls et al., 2020).

In some patients, SARS-CoV-2 can induce the socalled "cytokine storm": the phenomenon of immune-system hyperactivation (hypercytokinemia), which is uncontrolled and does not perform a protective function. Macrophages and neutrophiles (the main source of cytokines and chemokines) accumulate in the foci of CoV-2 infection. Proinflammatory cytokines IL-1, TNF, IL-6, and chemokines are synthesized in the focus of inflammation, mainly by macrophage cells. Chemokines enhance the directed migration of leukocytes to the focus of inflammation 
and, together with other cytokines, increase their functional activities: phagocytosis and the production of active oxygen radicals targeting pathogen elimination. Reactive oxygen particles (ROPs), which are released in excessive amounts, contribute to the development of oxidative stress, thereby stimulating the release of a new batch of cytokines. This process causes tissue destruction at the focus of inflammation; simultaneously, the reaction spreads to adjacent tissues and develops, becoming systemic and involving the entire organism (Walls et al., 2020).

Oxidative stress, a universal mechanism of cell damage, and inflammation are two processes that initiate and intensify each other (Ambade and Mandrekar, 2012). Such an inflammatory cascade leads to systemic oxidative stress and later causes structural changes in the lungs and other organs.

In some cases, the systemic inflammation provoked by the cytokine "storm" and the concomitant oxidative stress results in the death of a patient or an experimental model. At present, there is no specific therapy for such conditions.

Oxidative stress and inflammation in lungs are accompanied by the destruction of endothelial cells, alveolar epitheliocytes, and the basement membranes of epithelium. In response, alveolar macrophages release chemotactic factors for neutrophil recruitment and the replication of fibroblasts via the release of fibronectin and fibroblast growth factor, profibrotic cytokine TGF- $\beta 1$ (transforming growth factor), which is responsible for fibroblast proliferation and the migration and expression of collagen genes in the phase of fibrosis. The transition from fibroblast to myofibroblast occurs in the interstitium and the intraalveolar space of the lungs and leads to the formation and deposition of collagen fibers. Matrix metalloproteinases (MMPs) can cause the degradation of type-IV collagen and are probably associated with pulmonary fibrosis.

Sixty percent of COVID-19 patients have problems with functional bowel disorders (Jin et al., 2020; Lin et al., 2020; $\mathrm{Ng}$ and Tilg, 2020), i.e., the disease proceeds as a viral enteric disorder. This fact requires a deep and thorough study the role of the gut microbiota and the particular bacteria producing components of different natures that directly or indirectly influence resistance/susceptibility to the infection and severity of this process. The microbiota components with immunomodulating and anti-inflammatory activities are among such candidates.

In patients with diarrhea, viral particles were found in the upper layers of esophageal epithelium and in absorptive enterocytes from the ileum and the large intestine. Viral markers in stool samples are preserved for a longer time than in throat smears. The group with diarrhea more often exhibited additional symptoms: headache, myalgia or fatigue, cough, sputum production, nausea and vomiting, and a much longer period of fever and dyspnea. It is important that the administration of probiotics improves the symptoms of diarrhea. In the case of diarrhea, the integrity of the intestinal barrier can be impaired, which leads to an increase in systemic inflammation and oxidative stress. The potential consequences of this process may be cognitive impairment and the development of secondary, infectious, intestinal diseases as a result of microbiome disturbance and weakened immunity. Despite the more severe course of COVID-19 in patients with intestinal symptoms, their addition does not worsen the prognosis of lethality; potential predictors include enhanced levels of ferritin and IL-6, as well as a correlation with virus-induced hyperinflammation (Mehta et al., 2020).

The immune response to COVID-19 was described in detail in the reviews by Catanzaro (Catanzaro et al., 2020) and Florindo (Florindo et al., 2020); in the present review, we briefly describe the cytokines associated with this infection.

\section{CYTOKINES INVOLVED IN THE CYTOKINE STORM WITH COVID-19 INFECTION}

Cytokines are small (up to $30 \mathrm{kDa}$ ), secretory peptides and glycoproteins produced by different types of cells: lymphocytes, macrophages, granulocytes, reticular fibroblasts, and endothelial cells. Cytokines are active at low concentrations $(0.001 \mu \mathrm{g} / \mathrm{mL})$; they mediate extracellular interactions and function as extracellular ligands for specific receptors. The binding of cytokines to receptors goes through a series of intermediate stages to the activation of the transcription of particular genes. Cytokines influence the development and homeostasis of the immune system, control blood cell growth and differentiation, and participate in the nonspecific defense responses of the body, exerting an effect on inflammatory processes, blood clotting, and blood pressure (Lepennetier et al., 2019).

Over the past 25 years, cytokines have become important for medicine as diagnostic, prognostic, and therapeutic agents for human diseases. Though cytokines are currently studied in almost all biological disciplines, cytokine-mediated effects are predominant in immunology.

Cytokines can be divided into several groups based on the functional activity and the site of synthesis: chemokines, growth factors, and interleukins. Interleukins are synthesized mostly by white blood cells; they are part of the immune system and may have proinflammatory activity, which allows mobilization of the inflammatory response, an anti-inflammatory activity that limits inflammation, and an immunoregulatory activity. Let us consider several types of cytokines in more detail.

Interleukin-1 (IL-1). The IL-1 group includes IL- $\alpha$, IL-1 $\beta$, IL-18, IL-33, etc., as well as the IL-1 receptor 
antagonist (IL-1RA). At present, it is known that IL-1 is involved in several inflammatory diseases, such as obesity, atherosclerosis, cancer, viral and parasitic infections, autoinflammatory syndromes, and liver diseases. The predominant circulating isoform of IL-1 is IL-1 $1 \beta$, a powerful proinflammatory cytokine that plays a key role in the regulation of protection against infections and injuries. Structurally, it is a protein molecule. It is produced and secreted by different types of cells, e.g., fibroblasts and lymphocytes, but the overwhelming majority of studies have been focused on its production in cells of the innate immune system, such as monocytes and macrophages. IL-1 $\beta$ is produced as an inactive precursor, the socalled pro-IL-1 $\beta$, in response to the molecular motifs carrying pathogens, the so-called pathogen-activated molecular patterns (PAMPs). PAMPs act via pattern recognition receptors (PRRs) on macrophages to regulate the pathways that control gene expression (Lopez-Castejon and Brough, 2011).

IL-1 $\beta$ exerts an effect via binding to IL- 1 receptors on the cell surface. Another isoform, IL-1 $\alpha$, performs an autocrine function and currently attracts much attention. The IL-1RA antagonist serves as the bait to bind free IL-1 and to prevent its interaction with the receptor (Buckley et al., 2018).

Interleukin-6 (IL-6). IL-6 is a multifunctional cytokine that has both proinflammatory and antiinflammatory effects and plays a key role in human metabolism, the differentiation of autoimmune cells, the treatment of diseases, etc. It can be produced by almost all stromal cells and immune cells, including $\mathrm{B}$ cells, $\mathrm{T}$ cells, macrophages, monocytes, dendritic cells, mast cells, and other nonlymphoid cells such as fibroblasts, endothelial cells, keratinocytes, and glomerular mesangial and tumor cells. The main activators of IL-6 expression are IL- $1 \beta$ and tumor necrosis factor alpha (TNF- $\alpha$ ) (Jones and Jenkins, 2018). However, there are other methods to stimulate IL-6 synthesis, such as TLR, prostaglandins, adipokines, stress response, and other cytokines.

Interleukin-7 (IL-7). IL-7 is a member of the family of cytokines with the common $\gamma$ chain, which also includes interleukin-2 (IL-2), IL-4, IL-9, IL-15 and IL-21. Nonderivative bone marrow stromal cells and epithelial cells are the main sources of IL-7 (Gonçalves and Duarte, 2019). Similar to other members, IL-7 transduces signals via the triple complex formed by its unique $\alpha$-receptor, IL-7R $\alpha$ (CD127), and the common $\gamma c$ receptor. This interaction is stimulated by Janus kinase (JAK) and signal transducer and transcription (STAT) proteins, followed by the activation of the phosphoinositol-3 kinase (PI3K)/Akt or Src pathways to facilitate transcription of the target gene. There are two IL-7R forms, membrane-bound and soluble, that perform different functions. Membrane-bound IL-7R allows signal transduction by IL-7, while soluble IL-7R provides the control-modulation mechanism. It is supposed that the soluble IL-7R form can intensify signal transduction by IL-7 and autoimmunity. The signaling cascade initiated by $\gamma c$ interleukins and their receptors regulates the homeostasis of natural killers (NKs) and B and $T$ cells of the immune system (Nguyen et al., 2017). The activity and broad range of effects suggest that the introduction or neutralization of IL-7 allows modulation of the immune function in patients with lymphocyte depletion or even in case of autoimmune diseases.

Interleukin-10 (IL-10). IL-10 is an anti-inflammatory cytokine, an antagonist of some other cytokines that can suppress fever. Structurally, it is a protein molecule. IL-10 is produced by $\mathrm{T}$ cells, monocytes, macrophages, B cells, keratinocytes, etc. When interacting with $T$ cells, it can reduce the production of inflammatory cytokines and decrease the activity of macrophages, interferons, and tumor necrosis factor (TNF). At the same time, it stimulates the synthesis of immunoglobulin $\mathrm{E}$ ( $\mathrm{IgE})$, which is involved in the development of immune response. IL-10 promotes the development of the humoral element of the human immunoresponse, thereby determining the antipathogen defense and allergen tolerance. The anti-inflammatory effect of IL-10 is due to its ability to inhibit activation of the nuclear factor kappa B (NF-kB) and to suppress the $\mathrm{Tx}-1$ immunoresponse. It is necessary for the restoration of the immune status and tissue homeostasis after an inflammatory process. It is important to observe the IL-10 activity in elderly people, since age-related diseases progress against the background of long-term inflammation. Moreover, an increased level of IL-10 is an indicator of renal insufficiency. It exerts an effect on the course and development of ischemic heart disease. It plays a particular role in the protection of brain cells against ischemic injury, and its reduced level in the blood of stroke patients is considered an indication for administration of the drugs protecting brain cells. An increase in the IL-10 concentration in the blood of patients with tumors is an unfavorable indicator of intensification of tumor growth (Serebrennikova et al., 2012).

Tumor necrosis factor $\alpha$ (TNF- $\alpha)$. TNF- $\alpha$ is a proinflammatory cytokine; structurally, it is a protein molecule. TNF- $\alpha$-producing cells include monocytes, macrophages, $\mathrm{T}$ cells, keratinocytes, neutrophils, astrocytes, and endothelial and smooth muscle cells. The inducers can be bacterial products, phorbol esters, and polyelectrolytes. The cytotoxic effect of TNF- $\alpha$ is manifested as the induction of apoptosis and the generation of reactive oxygen species (ROS) and nitrogen oxide (NO). It is able to induce the synthesis of interferon $\gamma$ (IFN- $\gamma$ ), which stimulates immune cells. TNF- $\alpha$ is one of the participants of inflammation induction; via paracrine stimulation of IL-8 production, it intensifies angiogenesis and the secretion of prostaglandins and determines the synthesis of proteins of the acute phase of inflammation. 
The involvement of TNF- $\alpha$ in the development of the immunoresponse is determined by the enhanced proliferation of B and T cells; it increases the thymusdependent production of antibodies and inhibits the formation of immunological tolerance (Marko and Prka, 2013).

\section{PROBIOTICS, PREBIOTICS, AND POSTBIOTICS}

At an early stage of the development of microbiology, bacteria were considered, from a medical point of view, to be foreign "invaders" capable of causing various diseases. Accordingly, studies in microbiology were focused mainly on the elimination of bacteria with disinfecting agents, antibiotics, and other substances (Linares et al., 2016).

The initial discovery of the benefits of the presence of particular bacteria is associated with the name of E. Metchnikoff, a Nobel laureate who is recognized as a pioneer of the study of probiotics. In the early 20th century, E. Metchnikoff discovered that "beneficial" bacteria, especially lactic-acid bacteria, can exert a positive effect on digestion and the immune system (Marco et al., 2006). Continuing Metchnikoff's studies on the favorable effects of bacteria, Henri Tissier from the Pasteur Institute in France administered bifidobacteria to infants suffering from diarrhea after bifidobacteria had been found in the gut microbiota of breast-fed babies (Mazloom et al., 2019).

Probiotics are living microorganisms that, when ingested in sufficient amounts, provide a health benefit (Fijan, 2014; Wang et al., 2016). In 1995, G. Gibson introduced the term "prebiotic." Prebiotics are nondigestible oligosaccharides, such as fructooligosaccharides, galactooligosaccharides, lactulose, and inulin, that can stimulate the growth of beneficial intestinal bacteria, in particular, lactobacilli and bifidobacteria (Patel and DuPont, 2015). Postbiotics are unviable bacteria, bacterial cell structures, and metabolic products exerting positive effects on a host. Various metabolic products produced by postbiotics include shortchain fatty acids (SCFAs), polysaccharides, bacteriocins, functional peptides, proteins, etc. (Johnson et al., 2019). The term "metabiotics" was introduced simultaneously with the term "probiotics" (Shenderov, 2013). The term "metabiotics" implies microecological agents based on low-molecular structural components, metabolites, and signaling molecules of bacteria-probiotics. They have a synergistic effect on the structural and regulatory genes of the cells of a macroorganism and regulate metagenomic stability, the posttranslational modification of gene products, and epigenetic regulation for the maintenance of the general state of health (Singh et al., 2018). The terms "metabiotics" and "postbiotics" are similar and have the same meaning of identified active components in probiotics and established mechanisms of their action. In our studies, we use also the term "pharmbiotics."
Pharmbiotics are probiotics and their products with the identified active components and the known mechanism of action.

The vast majority of microorganisms currently recognized as probiotics are gram-positive bacteria. Probiotics primarily include specially selected strains of lactobacilli and bifidobacteria. Other groups of bacteria of the human gut microbiome-the so-called next generation probiotics-have also recently been actively studied (Chang et al., 2019). Probiotics and their ingredients (components) are used in the food and pharmaceutical industries in the following three ways: (1) in foodstuffs (fermented products) with the declared status "generally recognized as safe" (GRAS) for Lactobacillus, Bifidobacterium, and Lactococcus, which is established by the United States Food and Drug Administration (Mazloom et al., 2019); (2) as dietary supplements, often over-the-counter (OTC); and (3) as drugs (pharmaceutical agents). Categorization depends on the manufacturers of the probiotics and the indications for their administration, as well as the requirements set by different regulatory authorities (Sanders et al., 2018). The safety of foodstuffs or pharmaceutical agents intended to be eaten by humans, including probiotics, is the primary factor that makes it possible to avoid any health hazards. Some clinical studies have confirmed the safety of probiotics (with respect to the absence of toxicity) in different populations, including healthy adult volunteers, women in late pregnancy and their children at an early age (02 years old), children admitted to a hospital, and patients with weakened immunity. Probiotics a priori must be nonpathogenic, which means that they should never cause or aggravate any human disease, regardless of their source, i.e., foodstuffs or OTC additives (Žuntar et al., 2020).

Other bacterial probiotics, which are still being studied, include bacilli, enterococci, lactococci, and streptococci (Behnsen et al., 2013). In addition, the bacteria that can be potential probiotics include some gram-negative bacteria. The best example in this group is Escherichia coli Nissle 1917 (EcN1917), which is also known as Mutaflor. It has been used for many years in Germany to treat chronic constipation and colitis (Rijkers et al., 2011; Behnsen et al., 2013). The yeasts Saccharomyces cerevisiae and Saccharomyces boulardii are also used as probiotics (Azad et al., 2018). It should be emphasized that probiotic properties are characteristic not of all bacterial species but of individual strains, i.e., they are exceptionally strain-specific.

Probiotics have become widespread in the global market of health care; their circulation was 42.64 billion in 2017 and will probably reach 87.91 billion by 2026 (https://www.researchandmarkets.com/research/ fs 33 tg/global_probiotics? $w=5)$. There is a large number of probiotics containing various bacterial cocktails that have been developed to offer some health benefits, from the maintenance of homeostasis of the 
immune system (Fata et al., 2018) and the GIT (Dimidi et al., 2017), control of the serum cholesterol level (Ettinger et al., 2014), and the treatment of allergic diseases (Felice et al., 2008) to the treatment of mental disorders, such as anxiety and depression (Pirbaglou et al., 2016; Bastiaanssen et al., 2020; Cerdo et al., 2020).

It was shown that probiotic administration promotes the functioning of the intestinal barrier (Ohland and Macnaughton, 2010). For example, lactobacilli modulate the expression of numerous genes that encode the adherens junction proteins, such as E-cadherin and B-catenin in the T84 cell barrier model (Hummel et al., 2012). In addition, the probiotic EcN1917 not only prevents the impairment of the mucus barrier caused by pathogenic E. coli but also restores the integrity of T 84 and Caco- 2 cells. This effect was mediated by the enhanced expression and changes in the positions of tight junction proteins zonula occludens (ZO-2) and protein kinase $\mathrm{C}$ $(\mathrm{PKC})$, which resulted in the reconstruction of the complex of tight junctions (Zyrek et al., 2007). Some of the major macromolecular components of the epithelial lining fluid include mucin glycoproteins and may be important in the development of metabolic syndrome. Probiotics promoting mucus secretion can improve the gut-barrier function and eliminate pathogens. One example is the administration of probiotic VSL\#3 to rats for 7 days, which results in a 60 -fold increase in $M U C 2$ expression and enhanced mucin secretion. Moreover, VSL\#3 (the mixture of probiotics and prebiotics) jointly protects the epithelial barrier and increases the expression of tight junction proteins due to the activation of the p38 and extracellular kinase pathways (Dai et al., 2012).

The selection and assessment of probiotic candidates require a complex approach that includes several stages.

The first stage of the selection of strains of potential probiotics is an assessment of the common probiotic properties of the bacteria, usually in vitro. Strains are selected with respect to the ability to be maintained in a host organism. They must be resistant to enzymes, such as amylase and lysozyme, that are found in the oral cavity; they must withstand the specific environment of the stomach (low $\mathrm{pH}$ value, gastric juice, pepsin) and the bowel (pancreatin and bile acids). The ability of potential probiotics to colonize epithelial cells of the GIT is also assessed. The adhesion of microbes to epithelial cells is associated both with the capacity for autoaggregation and the hydrophobic properties of cell surface, which improve the interaction between bacteria and human epithelial cells. For example, it was demonstrated that some proteins of Lactobacillus facilitate adhesion to the mucous membrane. In addition, probiotics of this genus demonstrate surface adhesins that facilitate attachment to the mucous layer in the host gut. One such protein is mucus-binding protein (MUB) produced by Lactobacillus reuteri. Bifidobacterium animalis also has surface proteins that interact with human enterocytes and perform numerous functions, including the facilitation of colonization due to degradation of the extracellular matrix of cells or tight contact to the epithelial surface (Mazloom et al., 2019). It is highly important to understand the mechanisms of gut colonization under both normal and inflammatory conditions in order to develop probiotics for particular applications.

An important property is the ability to suppress the growth of pathogenic bacteria. When selecting probiotic strains, we assess their ability to produce active extracellular metabolites as a result of synthesis (hydrogen peroxide, bacteriocins, acetic and lactic acids, enzymes, low-molecular peptides, exopolysaccharides (EPS), etc.) and the transformation of carbohydrates, proteins, and other food components. It was shown that lactobacilli and bifidobacteria suppress numerous pathogens, including E. coli, Salmonella, Helicobacter pylori, Listeria monocytogenes, and rotavirus (Chenoll et al., 2011). One way that probiotics exert these effects is the steric modification of enterocyte receptors, which reduces the attachment of pathogenic bacteria (Coconnier et al., 1993).

The next stage is a safety assessment of the strains. There are several methods to assess probiotics. Particular attention can be focused on the internal (nonpathogenic) properties of various strains and species, their pharmacokinetic (PK) properties, and the strain-host interactions. Internal properties, such as deconjugation of the salts of bile acids, mucin degradation, or platelet aggregation, which are responsible for the colonization of heart valve and the production of undesirable metabolites that constitute a human health hazard, can be studied in vitro (Kothari et al., 2019). The probiotic survival rate that varies between different bacterial species, i.e., of a particular strain, is determined in vivo and in feces samples. Other techniques are intestinal intubation or mucous-membrane biopsy (Gao et al., 2020).

The Food and Agriculture Organization of the United Nations (FAO) and the World Health Organization (WHO) provided recommendations on the safety assessment of probiotics used in foodstuffs. Namely, it is recommended that probiotic strains should be characterized by a series of trials (strain specificity is related to probiotic effects) that allow the assessment of potential risks to human health. The series of trials includes testing of the antibiotic properties of resistance, the metabolic activity, and the formation of undesirable products, e.g., bile-salt deconjugation or D-lactate production. In addition, it should be possible to assess unfavorable effects for users in epidemiological studies, as well as to test the toxin production and the hemolytic activity of probiotics after their intake. The analyses should also test the probiotics properties in animal models with weak- 
ened immunity. In addition, the safety assessment of probiotics should also include the tests for antimutagenic, anticarcinogenic, nonpathogenic, and probiotic properties (Pradhan et al., 2020). Nevertheless, consultation of a healthcare expert is always justified in order to avoid any problems, irrespective of the causes of probiotic administration, especially in case of a serious disease or admission to a hospital, which requires careful patient observation.

Specific, useful (anti-inflammatory, immunomodulatory) properties of strains are then assessed (De Melo Pereira et al., 2018), and complex studies are carried out to select strains that simultaneously presenting the maximum number of functional properties and have no negative characteristics. The accumulated evidence demonstrating the relationship between the microorganism and aspects essential for human health and wellbeing has contributed to the development of new strategies of probiotic selection.

\section{IMMUNOBIOTICS IN THE CONTROL OF COVID-19: ADJUVANTS FOR VACCINES, PHARMBIOTICS FOR MICROBIOTA CORRECTION}

At present, an urgent problem in medical and biological sciences is the development of a tool of biological defense against viral pathogens of human respiratory diseases. In view of the rapid spread and high invasiveness of the new SARS-CoV-2 virus and the absence of effective therapeutic agents for its control, a high-priority task of the scientific and medical community is to develop preventive measures against COVID-19 infections among the population (Momtazmanesh et al., 2020).

Vaccination is considered the most efficient method for the prevention of such diseases. At present, active efforts are being made worldwide to develop a suitable vaccine against COVID-19, and more than 200 vaccine candidates are already being developed on the basis of different technological platforms and approaches (Le et al., 2020; Florindo et al., 2020). An effective vaccine must be able to induce the production of high-titer, neutralizing antibodies in order to prevent viral attachment to host-cell receptors. However, to reach protective levels, a vaccine can require multiple shots, high doses, or the assistance of the effects of other immunostimulating molecules, adjuvants. Adjuvants are assumed to be any compounds that exert a nonspecific effect and enhance the specific immunoresponse to antigens introduced together with these compounds. A suitable adjuvant included in vaccines not only should support the development of a strong immunoresponse but will also probably reduce the amount of antigen used and the need for multiple shots of additional vaccine doses.

At present, there are few adjuvants that have been developed and are currently used for vaccination.
However, it is exactly the adjuvants that improve cellmediated immunity, correct the immunoresponse in newborns and elderly people, improve the effects of single vaccine shots, and induce better cross-protective immunity. An ideal adjuvant stimulates the longterm protective response against the virus without reactogenicity or toxicity. The choice of effective adjuvant is now becoming increasingly crucial for the development and administration of particular types of vaccines (protein- and RNA-based) against COVID19. The results of experimental studies of an adjuvant vaccine against coronaviruses similar to SARS-CoV19 are already available (Gupta T. and Gupta S., 2020). Some pharmaceutical companies develop adjuvant vaccines, e.g., HaxSmith Kline, Segirus an Dynavax. They use the known licensed adjuvants: AS03, MF59, and CPG1018. However, the currently developed and used adjuvants are based on different chemical compounds (Gupta T. and Gupta S., 2020). However, various immunomodulating bacteria and their components, including carriers of pathogenassociated molecular patterns (PAMPs) that potentiate the immunoresponse, are also selected and tested as adjuvants. In particular, the adjuvant effects of lactic-acid bacteria (Pouwels et al., 1998), bacterial cellwall components (Bessler et al., 1997), fibronectinbinding protein 1 of Streptococcus pyogenes (Medina et al., 1998), surface-localized flagellins (Mizel and Bates, 2010), etc., have been described. The adjuvant effects of lactobacilli and bifidobacteria were demonstrated in the case of antiviral vaccination (Barbieri et al., 2013), antistreptococcal vaccination (Leontyeva et al., 2016), and antiallergic vaccination (van Overtvelt et al., 2012). It was shown that the intranasal administration of lactobacilli improves the local mucosal immunity and affects the systemic mechanisms of immune defense, increasing the resistance to infections caused by respiratory syncytial virus (Tomosada et al., 2013) or influenza virus. A promising current trend is to use probiotic microorganisms to boost the immune system and improve resistance to respiratory infections. The effects determined by the adjuvant and immunomodulatory effects of probiotics include an increased titer of specific antibodies, enhanced activity of Th1- and/or Th17-cells, and improved local mucosal immunity, in addition to protection against infections directly on the mucous membrane and via interaction with the innate immune system (Abdo et al., 2019).

Lactic-acid bacteria have been assessed as nonparenteral, live vaccine vectors. Clinical trials with the involvement of 50 volunteers showed that the peroral administration of the lactobacillus Lactobacillus fermentum CECT5716 improves the effects of vaccination against influenza, increasing the activity of Th1 cells and the level of vaccine-specific IgA after vaccination (Olivares et al., 2007). It was demonstrated that probiotics can induce IgA secretion to maintain immune surveillance (Lemme-Dumit et al., 2018). As 
representatives of the commensal microflora, probiotic lactobacilli are able to stimulate the mechanisms of immune defense by influencing changes in the secretion of both proinflammatory and anti-inflammatory cytokines.

Studies of the immunomodulating activity of bacterial strains in vitro are usually performed with cultures of intestinal cells (Caco-2, HT-29) or immunocytes (EC-6, THP-1). Such in vivo experiments are carried out with laboratory animals (healthy, with defects of the immune system, gnotobionts, and those with experimental infectious and noninfectious pathologies) (Fedorova and Danilenko, 2014).

Different studies have shown that bacteria capable of modulating intestinal and systemic immune responses can be used to prevent bacterial and viral respiratory infections (Eguchi et al., 2017). Peptidoglycan from the L. rhamnosus CRL1505 immunobiotic improved the innate respiratory, antiviral immunoresponse and reduced the transmigration of bacteria through the lungs and inflammatory lung injuries in newborn mice (Clua et al., 2017). The meta-analysis published by Hao et al. (Hao et al., 2015) and other researchers demonstrated the efficiency of probiotics in reducing the frequency and duration of acute respiratory infections of viral origin and the need for several courses of antibiotic therapy (King et al., 2019).

Probiotics can modulate the immune system by binding their cellular components: lipoteichoic acids, peptidoglycans, S-layer proteins, nucleic acids, etc., to TLR, NOD-like receptors and C-type lectin receptors expressed in the cells of the mucous membrane (Delgado et al., 2020). It is important that variations in the profiles of these cellular components differentially correlate with the immunomodulatory abilities of probiotic strains (Bron et al., 2012). Different fractions (postbiotics) isolated from the Bacillus coagulans culture (supernatant, cell wall fragments) induce the production of anti-inflammatory cytokines and the stimulation of T-helper (Th)2-dependent immune responses (Jensen et al., 2010). It should be noted that different strains of bifidobacteria and lactobacilli and their components have immunomodulatory effects of varying degrees of intensity (Averina et al., 2015). Tonetti et al. (Tonetti et al., 2020) demonstrated the strain-dependent adjuvant immunomodulatory effect on the example of the strain Lactobacillus rhamnosus CRL1505. The nasal administration of only the strain L. rhamnosus CRL1505 could improve both humoral and cellular adaptive immune responses induced by IFV infection or vaccination in mice. Higher levels of IFV-specific IgA and $\operatorname{IgG}$, as well as IFN- $\gamma$, were found in blood serum and in respiratory tracts.

To date, there are no publications on the assessment of probiotics as additional therapy in the case of COVID-19 infection. However, there are some studies on the interrelationship between the microbiome and susceptibility to COVID-19 (Gou et al., 2020), as well as assessment of the ability of various probiotic strains to reduce the viral load via different mechanisms of action. A research team in Belgium studies the potential of specific lactobacillus strains to reduce viral activity in the nasopharynx and oral cavity via reinforcement of the battier and the anti-inflammatory effect of the probiotic to reduce the risk of secondary bacterial infection with COVID-19 (International Scientific Association of Probiotics and Prebiotics Board of Directors, 2020). The review by Villena and Kitazawa (Villena and Kitazawa, 2020) summarizes the knowledge of the cellular and molecular mechanisms involved in the enhancement of antiviral protection of the respiratory apparatus via the effects of immunobiotic bacteria, e.g., Lactobacillus rhamnosus CRL1505. The ability of probiotic bacteria to improve the effects of type-I interferons and antiviral factors in respiratory tracts, the stimulation of Th1 cell response and antibody production, the regulation of inflammation and activation of blood clotting in the course of viral infection, the reduction of tissue injury, and the maintenance of respiratory function clearly indicate the potential of immunobiotics to exert a favorable effect on immunoresponse against the SARS-CoV-2 virus.

\section{CONCLUSIONS}

The COVID-19 pandemic compels humankind to mobilize the efforts of the world's scientists to solve the problem of its control and to overcome its shortand long-range consequences. In addition to the development of effective vaccines and adequate diagnostic agents, there is the problem of the creation of a new generation of immunomodulatory agents for COVID-19 prevention and treatment. A peculiar feature of this disease is the strong cytokine storm, which is followed by oxidative stress; it destroys various human organs, including the brain. These facts draw attention to the key functional impairment of the immune system, which leads to destructive inflammatory processes.

It is known that disturbance of the gut microbiota-dysbiosis-correlates with and probably leads to inflammatory processes (Levy et al., 2017; Tiffany and Bäumler, 2019), both in the gut and in other human organs and tissues. This fact suggests that the treatment of the cytokine storm, oxidative stress, and its consequences for all human organs and systems is possible with the involvement of the immunomodulatory and antioxidant potential of the microbiota. The microbiota can be corrected, primarily with the use of recently developed immunobiotics (Villena and Kitazawa, 2020, Dyakov et al., 2020) and probiotics with antioxidant potential (Marsova et al., 2018, 2020a, 2020b). The microbiome of stress-resistant people can be used as a source of a new generation of pharmbiotics and metabiotics based on them (Shenderov et al., 2019). Pharmbiotics can include not only 
live cultures of probiotic bacteria but also individual proteins that are capable of regulating, with some mechanism or another, the cytokine level in human body, e.g., as shown by Dyakov et al. (Dyakov et al., 2020), via the binding of the FN3 protein to the tumor necrosis factor.

The now obvious problem is to bring the microbiome of patients with dysbacteriosis to a condition that is close to normal before vaccination. At present, intensive work is being done to search for the compositions of the human-genome mutations that provide an organism with resistance to COVID-19. Since the immunomodulatory and antioxidant potentials of the human microbiome generally determine the homeostasis of the body and the potential resistance to COVID-19, one should search for microbiome biomarkers that can be used to detect this resistance. Studies are already being conducted in this respect (Gou et al., 2020). In contrast to genetic markers in the human genome, gut-microbiota biomarkers (bacteria and bacterial genes) are convenient objects for the development of the respective pharmbiotic agents.

\section{COMPLIANCE WITH ETHICAL STANDARDS}

Conflict of interests. The authors declare that they have no conflicts of interest.

Statement on the welfare of humans or animals. This article does not contain any studies involving animals performed by any of the authors.

\section{REFERENCES}

Abdo, Z., LeCureux, J., and Dean, J.A., Impact of oral probiotic Lactobacillus acidophilus vaccine strains on the immune response and gut microbiome of mice, PLoS One, 2019, vol. 14, p. e0225842.

Ambade, A. and Mandrekar, P., Oxidative stress and inflammation: essential partners in alcoholic liver disease, Int. J. Hepatol., 2012, vol. 2012, art. ID 853175.

Averina, O.V. and Danilenko, V.N., Human intestinal microbiota: role in development and functioning of the nervous system, Microbiology (Moscow), 2017, vol. 86, no. 1, pp. 5-24.

Averina, O.V., Ermolenko, E.I., Suvorov, A.N., et al., Influence of probiotics on cytokine production in the in vitro and in vivo systems, Med. Immunol., 2015, vol. 17, no. 5, pp. 443-454.

Averina, O.V., Kovtun, A., Danilenko, V.N., et al., The bacterial neurometabolic signature of the gut microbiota of young children with autism spectrum disorders, $J$. Med. Microbiol., 2020, vol. 69, no. 4, pp. 1-14.

Azad, A.K., Sarker, M., Li, T., and Yin, J., Probiotic species in the modulation of gut microbiota: an overview, BioMed Res. Int., 2018, vol. 2018, art. ID 9478630.

Barbieri, N., Villena, J., Herrera, M., Alvarez, S., et al., Nasally administered Lactobacillus rhamnosus accelerate the recovery of humoral immunity in B lymphocyte deficient malnourished mice, J. Nutr., 2013, vol. 143, pp. 227-235.
Barko, P.C., McMichael, M.A., Swanson, K.S., and Williams, D.A., The gastrointestinal microbiome: a review, J. Vet. Int. Med., 2018, vol. 32, no. 1, pp. 9-25.

Bastiaanssen, T., Cussotto, S., Cryan, J., et al., Gutted! Unraveling the role of the microbiome in major depressive disorder, Harv. Rev. Psychiatry, 2020, vol. 28, no. 1, pp. 26-39.

Behnsen, J., Deriu, E., and Raffatellu, M., Probiotics: properties, examples, and specific applications, Cold Spring Harb. Perspect. Med., 2013, vol. 3, no. 3, art. ID a010074.

Belkaid, Y. and Harrison, O.Y., Homeostatic immunity and the microbiota, Immunity, 2017, vol. 46, no. 4, pp. 562576.

Bessler, W.G., Huber, M., and Baier, M., Bacterial cell wall components as immunomodulators-II. The bacterial cell-wall extract OM-85 BV as unspecific activator, immunogen and adjuvant in mice, Int. J. Immunopharmacol., 1997, vol. 19, nos. 19-20, pp. 551-558.

Blumberg, R. and Powrie, F., Microbiota, disease, and back to health: a metastable journey, Sci. Transl. Med., 2012, vol. 4, no. 137, art. ID 137rv7.

Bron, P.A., van Baarlen, P., and Kleerebezem, M., Emerging molecular insights into the interaction between probiotics and the host intestinal mucosa, Nat. Rev. Microbiol., 2011, vol. 10, no. 1, pp. 66-78.

Buckley, L.F., Viscusi, M.M., van Tassell, B.W., and Abbate, A., Interleukin-1 blockade for the treatment of pericarditis, Eur. Heart J. Cardiovasc. Pharmacother., 2018, vol. 4, no. 1, pp. 46-53.

Catanzaro, M., Fagiani, F., Lanni, C., et al., Immune response in COVID-19: addressing a pharmacological challenge by targeting pathways triggered by SARSCoV-2, Signal Transduction Targeted Ther., 2020, vol. 5, p. 84.

Cerdo, T., Dieguez, E., and Campoy, C., Impact of gut microbiota on neurogenesis and neurological diseases during infancy, Curr. Opin. Pharmacol., 2020, vol. 50, pp. 33-37.

Chang, C., Lin, T., Lai, H., et al., Next generation probiotics in disease amelioration, J. Food Drug Anal., 2019, vol. 27, no. 3, pp. 615-622.

Cheng, L., Liu, Y., Tsai, Y., et al., Psychobiotics in mental health, neurodegenerative and neurodevelopmental disorders, J. Food Drug Anal., 2019, vol. 27, no. 3, pp. 632-648.

Chenoll, E., Casinos, B., Genoves, S., et al., Novel probiotic Bifidobacterium bifidum CECT 7366 strain active against the pathogenic bacterium Helicobacter pylori, Appl. Environ. Microbiol., 2011, vol. 77, no. 4, pp. 13351343.

Cianci, R., Pagliari, D., Gambassi, G., et al., The microbiota and immune system crosstalk in health and disease, Med. Inflammation, 2018, vol. 2018, art. ID 2912539.

Clua, P., Kanmani, P., Villena, J., et al., Peptidoglycan from immunobiotic Lactobacillus rhamnosus improves resistance of infant mice to respiratory syncytial viral infection and secondary pneumococcal pneumonia, Front. Immunol., 2017, vol. 10, no. 8, p. 948.

Coconnier, M.H., Bernet, M.F., Servin, A.L., et al., Adhering heat-killed human Lactobacillus acidophilus, strain LB, inhibits the process of pathogenicity of diar- 
rhoeagenic bacteria in cultured human intestinal cells, J. Diarrhoeal Dis. Res., 1993, vol. 11, no. 4, pp. 235242.

Cryan, J.F., O'Riordan, K.J., Dinan, T.G., et al., The microbiota-gut-brain axis, Physiol. Rev., 2019, vol. 99, no. 4, pp. 1877-2013.

Dai, C., Zhao, D.H., and Jiang, M., VSL\#3 probiotics regulate the intestinal epithelial barrier in vivo and in vitro via the p38 and ERK signaling pathways, Int. J. Mol. Med., 2012, vol. 29, no. 2, pp. 202-208.

Delgado, S., Sánchez, B., Ruiz, L., et al., Molecules produced by probiotics and intestinal microorganisms with immunomodulatory activity, Nutrients, 2020, vol. 12, no. 391, pp. 1-14.

De Melo Pereira, G.V., de Oliveira Coelho, B., Soccol, C.R., et al., How to select a probiotic? A review and update of methods and criteria, Biotechnol. Adv., 2018, vol. 36, no. 8 , pp. 2060-2076.

Derrien, M. and van Hylckama Vlieg, J.E., Fate, activity, and impact of ingested bacteria within the human gut microbiota, Trends Microbiol., 2015, vol. 23, no. 6, pp. 354-366.

Dharmage, S.C., Lodge, C.J., and Allen, K.J., Antibiotics and risk of asthma: a debate that is set to continue, Clin. Exp. Allergy, 2015, vol. 45, no. 1, pp. 6-8.

Dimidi, E., Christodoulides, S., and Whelan, K., Mechanisms of action of probiotics and the gastrointestinal microbiota on gut motility and constipation, $A d v$. Nutr., 2017, vol. 8, no. 3, pp. 484-494.

Dyakov, I.N., Mavletova, D.A., Danilenko, V.N., et al., FN3 protein fragment containing two type III fibronectin domains from B. longum GT15 binds to human tumor necrosis factor alpha in vitro, Anaerobe, 2020, vol. 65, art. ID 102247.

Eguchi, K., Fujitani, N., Nakagawa, H., and Miyazaki, T., Prevention of respiratory syncytial virus infection with probiotic lactic acid bacterium Lactobacillus gasseri SBT2055, Sci. Rep., 2019, vol. 9, no. 1, art. ID 4812.

Ettinger, G., MacDonald, K., Reid, G., and Burton, J.P., The influence of the human microbiome and probiotics on cardiovascular health, Gut Microbes, 2014, vol. 5, no. 6, pp. 719-728.

Fata, G.L., Weber, P., and Mohajeri, M.H., Probiotics and the gut immune system: indirect regulation, Probiotics Antimicrob. Proteins, 2018, vol. 10, no. 1, pp. 11-21.

Fedorova, I.A. and Danilenko, V.N., Immunogenic properties of a probiotic component of the human gastrointestinal tract microbiota, Biol. Bull. Rev., 2014, vol. 4, no. 6, pp. 457-466.

Felice, D.G., Barletta, B., Boirivant, M., et al., Use of probiotic bacteria for prevention and therapy of allergic diseases: studies in mouse model of allergic sensitization, J. Clin. Gastroenterol., 2008, vol. 3, no. 1, pp. 130132.

Fijan, S., Microorganisms with claimed probiotic properties: an overview of recent literature, Int. J. Environ. Res. Publ. Health, 2014, vol. 11, no. 5, pp. 4745-4767.

Florindo, H.F., Kleiner, R., Satchi-Fainaro, R., et al., Immune-mediated approaches against COVID-19, Nat. Nanotechnol., 2020, vol. 15, pp. 630-645.
Foster, J.A. and Neufeld, K.V., Gut-brain axis: how the microbiome influences anxiety and depression, Trends Neurosci., 2013, vol. 36, no. 5, pp. 305-312.

Fung, T.C., Olson, C.A., and Hsiao, E.Y., Interactions between the microbiota, immune and nervous systems in health and disease, Nat. Neurosci., 2017, vol. 20, no. 2, pp. 145-155.

Galdeano, C.M. and Perdigón, G., The probiotic bacterium Lactobacillus casei induces activation of the gut mucosal immune system through innate immunity, Clin. Vacc. Immunol., 2006, vol. 13, no. 2, pp. 219-226.

Gao, X., Liu, J., Sun, M., et al., A brief review of nutraceutical ingredients in gastrointestinal disorders: evidence and suggestions, Int. J. Mol. Sci., 2020, vol. 21, no. 5, p. 1822.

Gilbert, J.A., Quinn, R.A., Knight, R., et al., Microbiomewide association studies link dynamic microbial consortia to disease, Nature, 2016, vol. 535, no. 7610, pp. 94-103.

Gilbert, J.A., Blaser, M.J., Caporaso, J.G., et al., Current understanding of the human microbiome, Nat. Med., 2018, vol. 24, no. 4, pp. 392-400.

Gómez-Llorente, C., Muñoz, S., and Gil, A., Role of Tolllike receptors in the development of immunotolerance mediated by probiotics, Proc. Nutr. Soc., 2010, vol. 69, no. 3, pp. 381-389.

Gonçalves, R.S.G. and Duarte, A.L.B.P., IL-7 is a key driver cytokine in spondyloarthritis? J. Immunol. Res., 2019, vol. 2019, art. ID 7453236.

Gou, W., Fu, Y., Zheng, J., et al., Gut microbiota may underlie the predisposition of healthy individuals to COVID-19, medRxiv, 2020, art. ID ppmedrxiv20076091.

Gralinski, L.E. and Menachery, V.D., Return of the coronavirus: 2019-nCoV, Viruses, 2020, vol. 12, no. 2, p. 135.

Grosicki, G.J., Fielding, R.A., and Lustgarten, M.S., Gut microbiota contribute to age-related changes in skeletal muscle size, composition, and function: biological basis for a gut-muscle axis, Calcif. Tissue Int., 2018, vol. 102 , no. 4, pp. 433-442.

Gupta, T. and Gupta, S.K., Potential adjuvants for the development of a SARS-CoV-2 vaccine based on experimental results from similar coronaviruses, Int. Immunopharmacol., 2020, vol. 86, pp. 1-13.

Hao, Q., Dong, B.R., and Wu, T., Probiotics for preventing acute upper respiratory tract infections, Cochrane Database Syst. Rev., 2015, vol. 2, art. ID CD006895.

Hooper, D.U., Adair, E.C., O'Connor, M.I., et al., A global synthesis reveals biodiversity loss as a major driver of ecosystem change, Nature, 2012, vol. 486, no. 7401, pp. 105-108.

Hummel, S., Veltman, K., Schmidt, M.A., et al., Differential targeting of the E-cadherin/ $\beta$-catenin complex by gram-positive probiotic lactobacilli improves epithelial barrier function, Appl. Environ. Microbiol., 2012, vol. 78, no. 4, pp. 1140-1147.

Jensen, G.S., Benson, K.F., Carter, S.G., and Endres, J.R., GanedenBC $30^{\mathrm{TM}}$ cell wall and metabolites: anti-inflammatory and immune modulating effects in vitro, BMC Immunol., 2010, vol. 11, p. 15. 
Jin, X., Lian, J.S., Zhang, X.L., et al., Epidemiological, clinical and virological characteristics of 74 cases of coronavirus-infected disease 2019 (COVID-19) with gastrointestinal symptoms, Gut, 2020, vol. 69, no. 6, pp. 1002-1009.

Johnson, C.N., Kogut, M.H., Arsenault, R.J., et al., Administration of a postbiotic causes immunomodulatory responses in broiler gut and reduces disease pathogenesis following challenge, Microorganisms, 2019, vol. 7, no. 8 , pp. 268.

Jones, S.A. and Jenkins, B.J., Recent insights into targeting the IL-6 cytokine family in inflammatory diseases and cancer, Nat. Rev. Immunol., 2018, vol. 18, no. 12, pp. 773-789.

Kastl, A.J., Terry, N.A., Wu, G.D., and Albenberg, L.G., The structure and function of the human small intestinal microbiota: current understanding and future directions, Cell. Mol. Gastroenterol. Hepatol., 2020, vol. 9, no. 1, pp. 33-45.

King, S., Tancredi, D., Merenstein, D., et al., Does probiotic consumption reduce antibiotic utilization for common acute infections? A systematic review and metaanalysis, Eur. J. Publ. Health, 2019, vol. 29, no. 3, pp. 494-499.

Klimina, K.M., Voroshilova, V.N., Danilenko, V.N., et al., Toxin-antitoxin systems: a tool for taxonomic analysis of human intestinal microbiota, Toxins, 2020, vol. 12, no. 6, p. 388 .

Kothari, D., Patel, S., and Kim, S.K., Probiotic supplements might not be universally-effective and safe: a review, Biomed. Pharmacother., 2019, vol. 111, pp. 537547.

Le, T.T., Andreadakis, Z., Mayhew, S., et al., The COVID-19 vaccine development landscape, Nat. Rev., 2020, vol. 19, no. 5, pp. 305-306.

Lemme-Dumit, J.M., Polti, M.A., Galdeano, C.M., et al., Probiotic bacteria cell walls stimulate the activity of the intestinal epithelial cells and macrophage functionality, Benefic. Microbes, 2018, vol. 9, no. 1, pp. 153-164.

Leont'eva, G.F., Gramskaya, T.A., Suvorov, A.N., et al., Evaluation of Lactobacillus probiotics as adjuvants in nasal immunization with chimeric pneumococcal vaccine, Med. Immunol., 2016, vol. 18, no. 6, pp. 545-554.

Lepennetier, G., Hracsko, Z., and Kowarik, M.C., Cytokine and immune cell profiling in the cerebrospinal fluid of patients with neuro-inflammatory diseases, $J$. Neuroinflammation, 2019, vol. 16, p. 219.

Levy, M., Kolodziejczyk, A.A., Elinav, E., et al., Dysbiosis and the immune system, Nat. Rev. Immunol., 2017, vol. 17, no. 4, pp. 219-232.

Li, H., Liu, S., Tang, C., et al., Coronavirus disease 2019 (COVID-19): current status and future perspectives, Int. J. Antimicrob. Agents, 2020, vol. 55, no. 5, art. ID 105951.

Lin, L., Jiang, X., Mai, L., et al., Gastrointestinal symptoms of 95 cases with SARS-CoV-2 infection, Gut, 2020, vol. 69, no. 6 , pp. 997-1001.

Linares, D.M., Ross, P., and Stanton, C., Beneficial microbes: the pharmacy in the gut, Bioengineered, 2016, vol. 7, no. 1, pp. 11-20.
Lopez-Castejon, G. and Brough, D., Understanding the mechanism of IL-1 $\beta$ secretion, Cytokine Growth Factor Rev., 2011, vol. 22, no. 4, pp. 189-195.

Lozupone, C., Faust, K., Knight, R., et al., Identifying genomic and metabolic features that can underlie early successional and opportunistic lifestyles of human gut symbionts, Genome Res., 2012, vol. 22, no. 10, pp. 1974-1984.

Lu, Y., Li, X., Zhang, D., et al., Toll-like receptors and inflammatory bowel disease, Front. Immunol., 2018, vol. 9, p. 72.

Marco, M.L., Pavan, S., and Kleerebezem, M., Towards understanding molecular modes of probiotic action, Curr. Opin. Biotechnol., 2006, vol. 17, no. 2, pp. 204210.

Marko, B. and Prka, L., Anti-TNF therapy in treatment of luminal Crohn's disease, Acta Med. Croat., 2013, vol. 67 , no. 2, pp. 179-189.

Marsova, M., Abilev, S., Danilenko, V., et al., A bioluminescent test system reveals valuable antioxidant properties of lactobacillus strains from human microbiota, World J. Microbiol. Biotechnol., 2018, vol. 34, no. 27, pp. 1-9.

Marsova, M., Odorskaya, M., Danilenko, V., et al., The Lactobacillus brevis $47 \mathrm{f}$ strain protects the murine intestine from enteropathy induced by 5-fluorouracil, Microorganisms, 2020a, vol. 8, no. 6, p. 876.

Marsova, M., Poluektova, E., Danilenko, V., et al., Protective effects of Lactobacillus fermentum U-21 against paraquat-induced oxidative stress in Caenorhabditis elegans and mouse models, World J. Microbiol. Biotechnol., 2020b, vol. 36, no. 7, p. 104.

Mazloom, K., Siddiqi, I., and Covasa, M., Probiotics: how effective are they in the fight against obesity? Nutrients, 2019, vol. 11, no. 2, p. 258.

Medina, E., Talay, S.R., Chhatwal, G.S., and Guzman, C.A., Fibronectin-binding protein 1 of Streptococcus pyogenes is a promising adjuvant for antigens delivered by mycosal route, Eur. J. Immunol., 1998, vol. 28, no. 3, pp. 1069-1077.

Mehta, P., McAuley, D.F., Manson, J.J., et al., COVID-19: consider cytokine storm syndromes and immunosuppression, Correspondence, 2020, vol. 395, pp. 10331034.

Mizel, S.B. and Bates, J.T., Flagellin as an adjuvant: cellular mechanisms and potential, J. Immunol., 2010, vol. 185, no. 10, pp. 5677-5682.

Moal, V.L., Anti-infective activities of Lactobacillus strains in the human intestinal microbiota: from probiotics to gastrointestinal anti-infectious biotherapeutic agents, Clin. Microbiol. Rev., 2014, vol. 27, no. 2, pp. 167-199.

Momtazmanesh S., Ochs H.D., Rezaei N., et al., All together to fight COVID-19, Am. J. Trop. Med. Hyg., 2020, vol. 102, no. 6, pp. 1181-1183.

Montalban-Arques, A., Schryver, P.D., Galindo-Villegas, J., et al., Selective manipulation of the gut microbiota improves immune status in vertebrates, Front. Immunol., 2015, vol. 6, p. 512.

Mukhopadhya, I. and Segal, J.P., The gut virome: the "missing link" between gut bacteria and host immunity? Ther. Adv. Gastroenterol., 2019, vol. 12, art. ID 1756284819836620 . 
Ng, S.C. and Tilg, H., COVID-19 and the gastrointestinal tract: more than meets the eye, Gut, 2020, vol. 69, no. 6, pp. 973-974.

Nguyen, V., Mendelsohn, A., and Larrick, J.W., Interleukin-7 and immunosenescence, J. Immunol. Res., 2017, vol. 2017, art. ID 4807853.

Novik, G. and Savich, V., Beneficial microbiota. Probiotics and pharmaceutical products in functional nutrition and medicine, Microb. Infect., 2020, vol. 22, no. 1, pp. 8-18.

Ohland, C.L. and Macnaughton, W.K., Probiotic bacteria and intestinal epithelial barrier function, Am. J. Physiol.: Gastrointest. Liver Physiol., 2010, vol. 298, no. 6, pp. 807-819.

Oleskin, A.V. and Shenderov, B.A., Probiotics and psychobiotics: the role of microbial neurochemicals, Probiotics Antimicrob. Proteins, 2019, vol. 11, no. 4, pp. 10711085.

Olivares, M., Díaz-Ropero, M.P., Xaus, J., et al., Oral intake of Lactobacillus fermentum CECT5716 enhances the effects of influenza vaccination, Nutrition, 2007, vol. 23, no. 3, pp. 254-260.

Ottman, N., Smidt, H., de Vos, W.M., and Belzer, C., The function of our microbiota: who is out there and what do they do? Front. Cell Infect. Microbiol., 2012, vol. 2, p. 104.

Patel, R. and DuPont, H.L., New approaches for bacteriotherapy: prebiotics, new-generation probiotics, and synbiotics, Clin. Infect. Dis., 2015, vol. 60, no. 2, pp. 108-121.

Peri, F., Calabrese, V., and Cighetti, R., Synthetic molecules and functionalized nanoparticles targeting the LPS-TLR4 signaling: a new generation of immunotherapeutics, Pure Appl. Chem., 2012, vol. 84, pp. 97106.

Pirbaglou, M., Katz, J., Ritvo, P., et al., Probiotic supplementation can positively affect anxiety and depressive symptoms: a systematic review of randomized controlled trials, Nutr. Res., 2016, vol. 36, no. 9, pp. 889898.

Pouwels, P.H., Leer, R.J., Shaw, M., and Hejne den BakGlashouwer, M.J., Lactic acid bacteria as antigen delivery vehicles for oral immunization purposes, Int. J. Food Microbiol., 1998, vol. 41, no. 2, pp. 155-167.

Pradhan, D., Mallappa, P.H., and Grover, S., Comprehensive approaches for assessing the safety of probiotic bacteria, Food Control, 2020, vol. 108, art. ID 106872.

Rhee, S.H., Pothoulakis, C., and Mayer, E.A., Principles and clinical implications of the brain-gut-enteric microbiota axis, Nat. Rev. Gastroenterol. Hepatol., 2009, vol. 6, no. 5, pp. 306-314.

Rijkers, G.T., de Vos, W.M., and Marteau, P., Health benefits and health claims of probiotics: bridging science and marketing, Br. J. Nutr., 2011, vol. 106, no. 9, pp. 1291-1296.

Sanders, M.E., Merenstein, D., Merrifield, C.A., and Hutkins, R., Probiotics for human use, Nutr. Bull., 2018, vol. 43, pp. 212-225.

Serebrennikova, S.N., Seminskii, I.N., Semenov, N.V., and Guzovskaya, E.V., Interleukin-1 and interleukin-10 in regulation of inflammatory process, Sib. Med. Zh., 2012, no. 8, pp. 5-7.
Shenderov, B.A., Metabiotics: novel idea or natural development of probiotic conception, Microb. Ecol. Health Dis., 2013, vol. 24, p. 20399.

Shenderov, B.A., Tkachenko, E.I., Zakharchenko, M.M., and Sinitsa, A.V., Metabiotics: prospects, challenges and opportunities, Med. Alfavit, 2019, vol. 2, no. 13, pp. $43-48$.

Shreiner, A.B., Kao, J.Y., and Young, V.B., The gut microbiome in health and in disease, Curr. Opin. Gastroenterol., 2016, vol. 31, no. 1, pp. 69-75.

Singh, A., Vishwakarma, V., and Singhal, B., Metabiotics: the functional metabolic signatures of probiotics: current state-of-art and future research priorities-metabiotics: probiotics effector molecules, Sci. Res., 2018, vol. 9, no. 4, pp. 147-189.

Spor, A., Koren, O., and Ley, R., Unravelling the effects of the environment and host genotype on the gut microbiome, Nat. Rev. Microbiol., 2011, vol. 9, no. 4, pp. 279290.

Sze, M.A., Tsuruta, M., Hogg, J.C., et al., Changes in the bacterial microbiota in gut, blood, and lungs following acute LPS instillation into mice lungs, PLoS One, 2014, vol. 9, p. e111228.

Tada, A., Zelaya, H., Villena, J., et al., Immunobiotic Lactobacillus strains reduce small intestinal injury induced by intraepithelial lymphocytes after Toll-like receptor 3 activation, Inflammation Res., 2016, vol. 65, no. 10, pp. 771-783.

Talib, N., Mohamad, N.E., Alitheen, N.B., et al., Isolation and characterization of Lactobacillus spp. from kefir samples in Malaysia, Molecules, 2019, vol. 24, no. 14, art. ID 2606.

Tiffany, C.R. and Bäumler, A.J., Dysbiosis: from fiction to function, Am. J. Physiol.: Gastrointest. Liver Physiol., 2019, vol. 317, no. 5, pp. 602-608.

Tomosada, Y., Chiba, E., Zelaya, H., et al., Nasally administered Lactobacillus rhamnosus strains differentially modulate respiratory antiviral immune responses and induce protection against respiratory syncytial virus infection, BMC Immunol., 2013, vol. 14, no. 40, pp. 1-16.

Tonetti, F.R., Islam, M.A., Takahashi H., et al., Nasal priming with immunobiotic lactobacilli improves the adaptive immune response against influenza virus, Int. Immunopharmacol., 2020, vol. 78, pp. 1-12.

Turnbaugh, P.J., Quince, C., Gordon, J.I., et al., Organismal, genetic, and transcriptional variation in the deeply sequenced gut microbiomes of identical twins, Proc. Natl. Acad. Sci. U.S.A., 2010, vol. 107, no. 16, pp. 7503-7508.

Turnbaugh, P.J., Ley, R.E., Gordon, J.I., et al., The human microbiome project: exploring the microbial part of ourselves in a changing world, Nature, 2013, vol. 449, no. 7164, pp. 804-810.

van Overtvelt, L., Moussu, H., Horiota, S., et al., Lactic acid bacteria as adjuvants for sublingual allergy vaccines, Vaccine, 2010, vol. 28, no. 17, pp. 2986-2992.

Villena, J. and Kitazawa, H., The modulation of mucosal antiviral immunity by immunobiotics: could they offer any benefit in the SARS-CoV-2 pandemic? Front. Physiol., 2020, vol. 11, p. 699. 
Walls, A.C., Park, Y., Veesler, D., et al., Structure, function, and antigenicity of the SARS-CoV-2 spike glycoprotein, Cell, 2020, vol. 180, no. 2, pp. 281-292.

Wang, H., Lee, I.S., Braum, C., and Enck, P., Effect of probiotics on central nervous system functions in animals and humans: a systematic review, J. Neurogastroenterol. Motil., 2016, vol. 22, no. 4, pp. 589-605.

Wang, J., Li, F., and Tian, Z., Role of microbiota on lung homeostasis and diseases, Sci. China Life Sci., 2017, vol. 60, no. 12, pp. 1407-1415.

Wang, Y., Wang, Y., Chen, Y., and Qin, Q., Unique epidemiological and clinical features of the emerging 2019 novel coronavirus pneumonia (COVID-19) implicate special control measures, J. Med. Virol., 2020, vol. 92, no. 6 , pp. 568-576.

Weiss, P.H., Zilles, K., and Fink, G.R., When visual perception causes feeling: enhanced cross-modal processing in grapheme-color synesthesia, NeuroImage, 2005, vol. 28, pp. 859-868.

Yan, J. and Charles, J.F., Gut microbiota and IGF-1, Calcif. Tissue Int., 2018, vol. 102, no. 4, pp. 406-414.

Yan, R., Zhang, Y., Zhou, Q., et al., Structural basis for the recognition of SARS-CoV-2 by full-length human ACE2, Science, 2020, vol. 367, pp. 1444-1448.

Yarilin, A.A., Immunologiya: uchebnik (Immunology: Manual), Moscow: GEOTAR-Media, 2010.

Yunes, R.A., Poluektova, E.U., Danilenko, V.N., et al., Selection of gamma-aminobutyric acid producing Lactobacillus and Bifidobacterium symbiont strains as potential psychobiotics, Vestn. Ross. Univ. Druzhby Nar., Ser. Ekol. Bezop. Zhiznedeyat., 2016a, no. 4, pp. 67-79.

Yunes, R.A., Poluektova, E.U., Danilenko, V.N., et al., GABA production and structure of $\mathrm{gadB} / \mathrm{gadC}$ genes in
Lactobacillus and Bifidobacterium strains from human microbiota, Anaerobe, 2016b, vol. 42, pp. 197-204.

Yunes, R.A., Poluektova, E.U., Danilenko, V.N., et al., A multi-strain potential probiotic formulation of GABAproducing Lactobacillus plantarum 90sk and Bifidobacterium adolescentis 150 with antidepressant effects, Probiotics Antimicrob. Proteins, 2019, vol. 12, no. 3, pp. 973-979.

Zhang, H., Kang, Z., Zhan, J., et al., Digestive system is a potential route of COVID-19: an analysis of single-cell coexpression pattern of key proteins in viral entry process, Gut, 2020, vol. 69, no. 6, pp. 1010-1018.

Zhang, Z., Lv, J., Pan, L., and Zhang, Y., Roles and applications of probiotic Lactobacillus strains, Appl. Microbiol. Biotechnol., 2018, vol. 102, no. 19, pp. 8135-8143.

Zoetendal, E.G., Raes, J., Kleerebezem, M., et al., The human small intestinal microbiota is driven by rapid uptake and conversion of simple carbohydrates, ISME J., 2012, vol. 6, pp. 1415-1426.

Zumla, A., Rustomjee, R., Eskild, P., et al., Middle East respiratory syndrome-need for increased vigilance and watchful surveillance for MERS-CoV in sub-Saharan Africa, Int. J. Infect. Dis., 2015, vol. 37, pp. 77-79.

Žuntar, I., Petric, Z., Kovačević, D.B., and Putnik, P., Safety of probiotics: functional fruit beverages and nutraceuticals, Foods, 2020, vol. 9, no. 7, p. 947.

Zyrek, A.A., Cichon, C., Schmidt, M.A., et al., Molecular mechanisms underlying the probiotic effects of Escherichia coli Nissle 1917 involve ZO-2 and $\mathrm{PKC} \zeta$ redistribution resulting in tight junction and epithelial barrier repair, Cell Microbiol., 2007, vol. 9, no. 3, pp. 804-816.

Translated by E. Makeeva 